\title{
ELECTROPHORESIS
}

\section{Microemulsion Electrokinetic Chromatography as a suitable tool for lipophilicity determination of acidic, neutral, and basic compounds.}

\begin{tabular}{|r|l|}
\hline Journal: & ELECTROPHORESIS \\
\hline Manuscript ID & elps.201600080.R1 \\
\hline Wiley - Manuscript type: & Research Paper \\
\hline Date Submitted by the Author: & O5-Apr-2016 \\
\hline Complete List of Authors: & $\begin{array}{l}\text { Subirats, Xavier; University of Barcelona, Department of Analytical } \\
\text { Chemistry } \\
\text { Yuan, Hui-Ping; University of Barcelona, Department of Analytical } \\
\text { Chemistry } \\
\text { Chaves, Verónica; University of Barcelona, Department of Analytical } \\
\text { Chemistry } \\
\text { Marzal, Núria; University of Barcelona, Department of Analytical Chemistry } \\
\text { Rosés, Martí; University of Barcelona, Department of Analytical Chemistry }\end{array}$ \\
\hline Keywords: & \begin{tabular}{l} 
lipophilicity, log Po/w, MEEKC, microemulsion, capillary electrophoresis \\
\hline
\end{tabular} \\
\hline
\end{tabular}




\section{Microemulsion Electrokinetic Chromatography as a suitable tool for lipophilicity} determination of acidic, neutral, and basic compounds.

Xavier Subirats, Hui-Ping Yuan, Verónica Chaves, Núria Marzal, Martí Rosés*

Departament de Química Analítica and Institut de Biomedicina (IBUB), Universitat de

Barcelona, Martí i Franquès 1-11, E-08028 Barcelona, Spain

*Corresponding author.

Dr. Xavier Subirats

Phone: (+34) 934039 119. Fax: (+34) 934021 233. E-mail: xavier.subirats@ub.edu

Ms. Hui-Ping Yuan

Current address:

Department of Medical Research, National Taiwan University Hospital

No.7, Chung Shan S. Rd. (Zhongshan S. Rd.), Zhongzheng Dist., Taipei City 10002, Taiwan E-mail: hpyuan@ntuh.gov.tw

Ms. Verónica Chaves

E-mail: vero3bcn@gmail.com

Ms. Núria Marzal

E-mail: nmarzalalb@gmail.com

Prof. Martí Rosés

Phone: (+34) 934039 275. Fax: (+34) 934021 233. E-mail: marti.roses@ub.edu

Total number of words including figure and table legends: $\sim 3700$ 


\begin{abstract}
In the present work, several MEEKC systems are studied to assess their suitability for lipophilicity determination of acidic, neutral and basic compounds. Thus, several microemulsion compositions over a wide range of $\mathrm{pH}$ values (from 2.0 to 12.0), containing heptane, 1-butanol and different types and amounts of surfactant (sodium dodecyl sulfate or sodium cholate: from $1.3 \%$ to $3.3 \%$ ) are characterized using Abraham's solvation model. The addition of acetonitrile (up to 10\%) is also studied, since it increases the resolution of the technique for the most lipophilic compounds. The system coefficients obtained are very similar to those of the 1-octanol/water, used as the reference lipophilicity index, allowing simple and linear correlations between the 1-octanol/water partition values $\left(\log P_{\mathrm{o} / \mathrm{w}}\right)$ and MEEKC mass distribution ratios ( $\log k_{\text {MEEKC }}$ ). Variations in the ME composition (aqueous buffer, surfactant, concentration of ACN) did not significantly affect the similarity of the MEEKC systems to $\log P_{\mathrm{o} / \mathrm{w}}$ partition.
\end{abstract}

\title{
KEYWORDS
}

Capillary electrophoresis, lipophilicity, $\log P_{\mathrm{o} / \mathrm{w}}$, MEEKC, microemulsion.

\author{
ABBREVIATIONS \\ DMSO: dimethyl sulfoxide \\ ME: microemulsion \\ SC: sodium cholate \\ SDS: sodium dodecylsulfate
}




\section{INTRODUCTION}

Lipophilicity is a physicochemical property that it is fundamental to determine in the drug discovery process, because the capacity of a specific compound to penetrate a lipid membrane and reach a proposed target is a key factor for the potential of a drug candidate. The partition ratio between the immiscible phases 1 -octanol and water, $\log P_{\mathrm{o} / \mathrm{w}}$, is the most widely used lipophilicity index; but reference methods are excessively time consuming for screening purposes and require a sample of high-purity. Traditional chromatographic methods may overcome these drawbacks, but most systems lack of a general simple correlation to $\log P_{\mathrm{o} / \mathrm{w}}$ and can be applicable only over a limited $\mathrm{pH}$ range due to degradation of the column under extreme acidic and basic conditions.

In 1995, Ishihama and coworkers [1] evaluated the suitability of MEEKC for the lipophilicity determination of neutral compounds. A microemulsion (ME) consisting of $1.44 \%$ (w/w) SDS, 6.49\% (w/w) 1-butanol and $0.82 \%(\mathrm{w} / \mathrm{w})$ heptane in $0.1 \mathrm{M}$ borate-0.05 M phosphate buffer, $\mathrm{pH}$ 7.0, was evaluated using phenols and heterocyclic bases (pyrimidines, pyrazines, pyrroles, indoles, and furans) as solutes. The study concluded that the mass distribution ratios obtained by MEEKC in the particular ME assayed were linearly correlated with the reference $\log P_{\mathrm{o} / \mathrm{w}}$ scale, even in the case of compounds with significant hydrogenbond properties. This is a very interesting advantage of MEEKC over other chromatographic techniques, such as reversed-phase liquid chromatography, which requires the experimental determination (or the estimation from computer programs and the consequent loss of accuracy) of hydrogen-bond acidity descriptors [2-4]. Moreover, in that pioneering study, the ME was considered to be a more reasonable biomembrane model than octanol/water or micellar systems. In fact, both ME and octanol/water are two-phase systems; but in the former the phases are apparently miscible, whereas the principle of $\log P_{\mathrm{o} / \mathrm{w}}$ determination is based precisely on a clearly visible separation between the aqueous and organic phase and the partition of the analytes between them. The oil-in-water ME consisted of heptane droplets dispersed in an aqueous buffer, mainly stabilized by the surfactant sodium dodecyl sulfate (SDS), but also by the cosurfactant 1-butanol. The surfactants coat the heptane droplets and lower the surface tension between oil and water, allowing the formation of a thermodynamically stable single-phase solution [5].

MEEKC is indeed a very interesting technique for studying compounds of biological interest, with a broad field of applications besides lipophilicity determination including chiral separations. For further details of recent developments and applications of MEEKC, readers can refer to the reviews published by Altria and coworkers [6-9]. As in conventional 
chromatography, the characteristic parameter of the partition of analytes between the mobile and the pseudo-stationary oil phase in the ME is the logarithm of the mass distribution ratio $\left(\log k_{\text {MEEKC }}\right)$, defined as [10]:

$$
\log k_{\mathrm{MEEKC}}=\log \frac{t_{\mathrm{R}}-t_{\mathrm{EOF}}}{t_{\mathrm{EOF}}\left(1-\frac{t_{\mathrm{R}}}{t_{\mathrm{ME}}}\right)}
$$

where $t_{\mathrm{R}}$ and $t_{\mathrm{EOF}}$ are the migration times of the analyte and the EOF marker (e.g. DMSO), respectively. $t_{\mathrm{ME}}$ is the migration time of the ME marker: a highly lipophilic analyte that remains in the oil phase during the entire run since it is not expected to partition into the aqueous phase (e.g. dodecanophenone, with a calculated $\log P_{\mathrm{o} / \mathrm{w}}$ of 6.87 [11]).

As indicated above, both MEEKC and traditional techniques to measure $\log P_{\mathrm{o} / \mathrm{w}}$ are based on the partition of the solute between two phases. The questions to be addressed are just how similar they are, and how can changes in the ME composition affect the system properties, and thus the similarity with $\log P_{\mathrm{o} / \mathrm{w}}$ partition. A very suitable tool to address these questions is the solvation parameter model developed by Abraham, which relates a solvation property $(S P)$, in our case the $\log P_{\mathrm{o} / \mathrm{w}}$ or the $\log k_{\mathrm{MEEKC}}$, with the sum of specific interaction terms [12]:

$$
\log S P=c+e E+s S+a A+b B+v V
$$

where $E, S, A, B$, and $V$ are the solute descriptors; and $c, e, s, a, b$, and $v$ are the system constants. Briefly, $E$ is the excess molar refraction (i.e., difference between the molar refraction of a particular solute and that of an alkane of equivalent volume) which models the dispersion force interactions arising from the greater polarizability of $\pi$ and $n$ electrons. $S$ accounts for the solute dipolarity/polarizability due to interactions between dipoles and induced dipoles. $A$ and $B$ are the solute hydrogen-bond acidity and basicity descriptors, respectively. Finally, $V$ is the McGowan's volume of the molecule. The coefficients $e, s, a, b$, and $v$ reflect the complementary effect of the solute descriptors on the solvent phases, providing chemical information that allows the characterization of the system.

In pioneering work [13] on the characterization of a MEEKC system using the solvation parameter model, $\log k_{\text {MEEKC }}$ values from the study by Ishihama mentioned above [1] were correlated with the descriptors of the solutes $(E, S, A, B$, and $V)$ by means of Eq. (2), leading to the following expression:

$$
\begin{gathered}
\log k_{\mathrm{MEEKC}}=-1.133+0.279 E-0.692 S-0.060 A-2.805 B+3.048 \mathrm{~V} \\
\left(n=53, R^{2}=0.988, S E=0.09\right)
\end{gathered}
$$


The coefficients in Eq. (3) were in fact smaller than those obtained for $\log P_{\mathrm{o} / \mathrm{w}}$ by Abraham in previous work [14]:

$$
\begin{gathered}
\log P_{\mathrm{o} / \mathrm{w}}=0.088+0.562 E-1.054 S+0.034 A-3.460 B+3.814 V \\
\left(n=613, R^{2}=0.995, S E=0.12\right)
\end{gathered}
$$

However, the relative values of the coefficients $(e / v, s / v, a / v$, and $b / v)$ were very similar; suggesting that the solute factors that influence the mass distribution ratio in MEEKC are in good agreement with those of the partition ratio between octanol and water.

As concluded from Eqs. (3) and (4), polar solutes with hydrogen-bond acceptor properties $(B>0)$ have the tendency to partition into the aqueous phase (the negative coefficient reduces the $\log k$ and $\log P_{\mathrm{o} / \mathrm{w}}$ values), whereas solutes with lone electron pairs $(S>0)$ and high molecular volume $(V>0)$ favor the oil phase (positive $e$ and $v$ coefficients, respectively). In contrast, the coefficient of hydrogen-bond acidity is close to zero and therefore it plays little role in the solute partition. In summary, the coefficients of both systems were similar and consequently the partition of solutes between the aqueous phase of the ME and its oil droplets (pseudo-stationary phase) was shown to be comparable to that between 1-octanol and water, meaning that the particular ME used in that study was a good model for the determination of lipophilicity.

\section{MATERIALS AND METHODS}

\subsection{Instrumentation}

A 3D CE Agilent (Waldbronn, Germany) instrument with UV detection and a 0-30 kV adjustable power supply was used in the present work. Polyimide coated capillaries of $50 \mu \mathrm{m}$ id, $375 \mu \mathrm{m}$ od (Polymicro Technologies, Phoenix, USA) of total lengths of 27, 37, and $57 \mathrm{~cm}$ were used depending on the ME employed. The cassette temperature was set to $25^{\circ} \mathrm{C}$ (forced air), and injections were performed applying a pressure of $50 \mathrm{mbar}$ for 5 to $10 \mathrm{~s}$, depending on the capillary length. Positive polarities were used at neutral and basic $\mathrm{pH}$ values, and negative polarity at acidic $\mathrm{pH}$. The applied voltages were selected for each ME composition and capillary length to be as high as possible but without a significant Joule effect (data not shown), in the range between 8 and $22 \mathrm{kV}$, in order to obtain typical current intensities of some $30 \mu \mathrm{A}$. External pressure up to 50 mbar was applied during the runs when necessary. Capillary preconditioning was performed by BGE for $2 \mathrm{~min}$, postconditioning by $1 \mathrm{M}$ sodium hydroxide and water for 2 min each. Measurements were taken at least in duplicate. 
Note that bare fused silica capillaries were used even at $\mathrm{pH}$ 2. External pressure and negative polarity were applied in order to compensate for the reversion of the EOF.

pH measurements were taken with a Crison (Barcelona, Spain) 5014 combination electrode (glass electrode and a reference electrode with a $3.0 \mathrm{~mol} \mathrm{~L}^{-1} \mathrm{KCl}$ solution in water as salt bridge) in a Crison GLP22 pH meter. MEs were sonicated in a J.P. Selecta (Barcelona, Spain) ultrasonic bath with a power of $360 \mathrm{~W}$.

\subsection{ME preparation}

Aqueous buffers were prepared from phosphoric acid (Merck, 85\%), sodium dihydrogenphosphate (Merck, for analysis), sodium hydrogenphosphate (J. T. Baker, 99.5\%), and boric acid (Fluka, $\geq 99.0 \%$ ). The $\mathrm{pH}$ was adjusted by the addition of small volumes of a $3 \mathrm{M} \mathrm{NaOH}$ solution prepared shortly before use from pellets (Merck, for analysis). Water was deionized to a resistivity of $18.2 \mathrm{M} \Omega \mathrm{cm}$ by the Milli- $\mathrm{Q}^{\circledR}$ plus system from Millipore (Billerica, MA, USA)

Under magnetic stirring and at room temperature, $1.3 \%$ or $3.3 \%(\mathrm{w} / \mathrm{v})$ of SDS (Merck, $\geq$ $99 \%$ ) was dissolved in the aqueous buffer $\left(20 \mathrm{mM} \mathrm{H} \mathrm{H}_{3} \mathrm{PO}_{4} / \mathrm{H}_{2} \mathrm{PO}_{4}^{-} \mathrm{pH} 2.0,10 \mathrm{mM}\right.$ $\mathrm{H}_{2} \mathrm{PO}_{4}^{-} / \mathrm{HPO}_{4}^{2-}$ pH 7.4, $20 \mathrm{mM} \mathrm{H} \mathrm{BO}_{3} / \mathrm{H}_{2} \mathrm{BO}_{3}^{-}$pH 10.0 or $\left.10 \mathrm{mM} \mathrm{HPO} \mathrm{HPO}_{4}^{2-} / \mathrm{PO}^{3-} \mathrm{pH} 12.0\right)$ until a transparent colorless solution was obtained. Then 1-butanol (Sigma-Aldrich, $\geq 99.4 \%$ ) was added up to $8.15 \%(\mathrm{v} / \mathrm{v})$, followed by heptane (Sigma-Aldrich, $\geq 99 \%$ ) up to $1.15 \%(\mathrm{v} / \mathrm{v})$. Both organic solvents were slowly added with a burette. At this point, the solution became white and turbid. Magnetic stirring was maintained for 5 minutes and then the ME was sonicated until it became clear again. Prolonged sonication can lead to progressive warming of the bath, which does not damage the ME. Finally the solution was left to stand at room temperature for at least 1 hour. Immediately before use as BGE, the ME was filtered using a $0.45 \mu \mathrm{m}$ nylon syringe filter (Simplepure, Membrane-Solutions, USA).

If required, in order to increase the resolution for lipophilic solutes, the desired volume of $\mathrm{ACN}$ up to $10 \%(\mathrm{v} / \mathrm{v})$ was mixed with the ME immediately prior to use and just before the filtering step.

ME stock solutions were stored in the laboratory at room temperature and light protected; under these conditions the ME studied remained clear and usable for at least 4 months.

\subsection{Sample preparation}


The ME marker, dodecanophenone, was directly solved by sonication in the same ME composition with the BGE at a concentration of $0.1-0.5 \mathrm{mg} / \mathrm{mL}$. Then the neutral marker (DMSO) was added, followed by the analytes from a stock solution solved in methanol $(\geq 5$ $\mathrm{mg} / \mathrm{mL})$ to a final concentration of $0.05-0.1 \%(\mathrm{v} / \mathrm{v})$ and $0.1-0.5 \mathrm{mg} / \mathrm{mL}$, respectively. It is convenient to limit the volume of methanol in the sample in order to avoid any destabilizing effect of the organic solvent and to minimize the differences between the sample and BGE compositions. Finally the samples were filtered prior to use.

The injected compounds (Table 1) were purchased from J.T. Baker, Carlo Erba, Fluka, Merck, Sigma-Aldrich, and Schuhardt; all of high purity grade.

\section{RESULTS AND DISCUSSION}

\subsection{Effect of the ME composition on the system}

In the present work, MEs prepared from different buffers representing a wide range of $\mathrm{pH}$ values (from 2.0 to 12.0 ), with different concentrations of surfactant $(1.3 \%$ or $3.3 \%)$ and ACN (from 0 to 10\%) were characterized using Abraham's solvation model (Eq. (2)). As the MEEKC approach requires the molecule in its neutral form, it is necessary to study the applicability of the method in a wide range of $\mathrm{pH}$ values. Acidic MEs are convenient for carboxylic and other acids with low $\mathrm{p} K_{\mathrm{a}}$ values; while high $\mathrm{pH}$ media are suitable for phenolic compounds and bases. Meanwhile, the surfactant concentration plays a key role in the stability of the ME and defines the instrumental separation conditions. Less of the anionic surfactant SDS reduces the ionic strength of the BGE and consequently a higher electric field can be applied, increasing the resolution and shortening the run times. In contrast, higher concentrations of SDS improve the ME stability and shorten the preparation time. This brings us to the question of whether variations in the surfactant concentration may affect the ME behavior for the determination of lipophilicity. Thus, in the present work, two different SDS concentrations $(1.3 \%$ and $3.3 \%)$ were assayed at three $\mathrm{pH}$ values $(7.4,10.0$, and 12.0). Finally, the addition of an organic solvent such as ACN might increase the resolution in the analysis of lipophilic compounds, whose peaks might migrate very close to that of the ME marker. Therefore, the effect of $\mathrm{ACN}$ concentration on the ME system was examined at $\mathrm{pH}$ 10 , through the addition of $5 \%$ and $10 \%(\mathrm{v} / \mathrm{v})$ of this organic modifier.

The results obtained for all the systems studied are presented in Table 2. In all cases, the molecular volume of the solute is the main property leading to a high affinity for the oil phase, since the $v$ coefficients are the largest with positive signs. Therefore, the formation of a cavity to accommodate the solute in the oil droplet requires less energy than it does in the 
bulk aqueous solvent. In contrast, as revealed by the negative and large $b$ coefficients, molecules exhibiting hydrogen-bond acceptor properties are better stabilized in the aqueous solutions by hydrogen-bonding. To a lower degree, polar or polarizable solutes have the tendency to partition into the aqueous phase, which exhibits a higher relative permittivity; whereas interactions based on non-bonding solute electrons are favored in the oil phase. The $a$ coefficients corresponding to the hydrogen-bond acidity of the solute are mainly negative, but in all cases with values very close to zero. This suggests that the hydrogen-bond acceptor properties of the oil and the aqueous phase are similar.

Table 2 reveals that neither changes in the $\mathrm{pH}$, concentration and nature of the aqueous buffer nor the addition of ACN significantly affect any of the system coefficients. Even the amount of surfactant has a very little effect on them, only affecting the $c$ constant, which increases with increasing SDS concentration. This might be related to an increase in the phase ratio due to more ME droplets.

With the aim of comparing the different MEEKC systems assayed with the reference $\log P_{\mathrm{o} / \mathrm{w}}$ (Eq. (4)), the $d$ distance parameter was calculated [15] and is also presented in Table 2. Briefly, if each system (Eq. (2)) is considered as a vector in a five-dimensional space, each component of the vector ( $e, s, a, b$, and $v$ ) can be normalized by dividing by the length of the vector $(l)$ to obtain unit vectors $\left(e_{\mathrm{u}}, s_{\mathrm{u}}, a_{\mathrm{u}}, b_{\mathrm{u}}\right.$, and $\left.v_{\mathrm{u}}\right)$, and then $d$ is the Euclidean distance between the two unit vectors being compared:

$$
\begin{aligned}
& l=\sqrt{e^{2}+s^{2}+a^{2}+b^{2}+v^{2}} \\
& d=\sqrt{\left(e_{\mathrm{u}, \mathrm{i}}-e_{\mathrm{u}, \mathrm{j}}\right)^{2}+\left(s_{\mathrm{u}, \mathrm{i}}-s_{\mathrm{u}, \mathrm{j}}\right)^{2}+\left(a_{\mathrm{u}, \mathrm{i}}-a_{\mathrm{u}, \mathrm{j}}\right)^{2}+\left(b_{\mathrm{u}, \mathrm{i}}-b_{\mathrm{u}, \mathrm{j}}\right)^{2}+\left(v_{\mathrm{u}, \mathrm{i}}-v_{\mathrm{u}, \mathrm{j}}\right)^{2}}
\end{aligned}
$$

It is convenient to normalize the system vectors because of the different magnitudes of log $P_{\mathrm{o} / \mathrm{w}}$ and $\log k_{\mathrm{MEEKC}}$. In fact, for the solutes studied in this work, the $\log P_{\mathrm{o} / \mathrm{w}}$ values were in

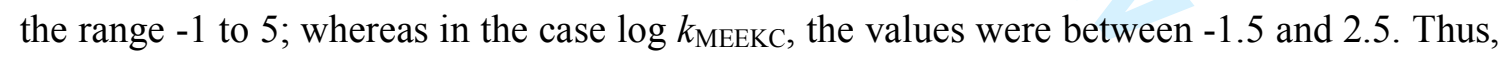
$d$ provides a mathematical measure of the similarity between two systems; the closer to $0 d$ is, the more similar the systems are. As shown in Table 2 , provided $d$ is very close to $0(d \leq$ 0.16), it can be concluded that MEEKC systems are similar enough to the octanol/water system to be well and linearly correlated. In fact, Figure 1A confirms the correspondence between the normalized coefficients $\left(e_{\mathrm{u}}, s_{\mathrm{u}}, a_{\mathrm{u}}, b_{\mathrm{u}}\right.$, and $\left.v_{\mathrm{u}}\right)$ of all the ME compositions summarized in Table 2 , and the reference $\log P_{\mathrm{o} / \mathrm{w}}$, demonstrating graphically the similarity between the systems.

In a study conducted by Poole and coworkers [16], several ME systems consisting of two different surfactants, SDS and sodium cholate (SC), at several $\mathrm{pH}$ values were 
characterized at $30^{\circ} \mathrm{C}$ using a reduced version of Eq. (2) without the hydrogen-bond acidity term, which was considered not to be statistically significant. In the present work, the log $k_{\text {MEEKC }}$ data and molecular descriptors published in that paper have been fitted to Eq. (2), and the results are presented in Table 2. In all cases, similar system coefficients and good correlations were obtained $\left(R^{2}>0.94\right)$. Only minor differences were observed for the system hydrogen-bond basicity coefficients ( $a$; notice that this is the complementary property of the solute hydrogen-bond acidity) depending on the surfactant used. In the case of SDS, the coefficients were slightly negative, whereas for SC they were nearly zero. However, the selection of a different surfactant only has a moderate influence in the hydrogen-bond basicity of the system, which does not really increase the difference between MEEKC and the octanol/water systems, or significantly affect their normalized coefficients (Figure 1B). The comparison of the results obtained in this study with those compiled from Poole's work [16] at $\mathrm{pH} 7,8,9$, and 12 , demonstrates that the selected $\mathrm{pH}$ and surfactant concentration do not affect the system properties. In view of this and the benefits of a reduction in ionic strength, $1.3 \%$ of SDS seems recommendable.

As a consequence of the similarity between octanol/water and MEEKC systems, assessed in the present work by means of Abraham's solvation model, linear correlations were observed for all the ME compositions studied, as shown in Figure 2 for some representative examples.

\subsection{Concluding remarks}

Octanol-water partition systems and MEs have very similar physicochemical properties, as demonstrated by means of Abraham's solvation parameter model. Variations in the composition ( $\mathrm{pH}$, buffer nature, surfactant type and concentration, etc.), and even the addition of ACN, do not significantly change the properties of the ME. Therefore, simple linear correlations can be established between $\log k_{\text {MEEKC }}$ measurements and $\log P_{\mathrm{o} / \mathrm{w}}$, indicating that MEEKC is a suitable tool for lipophilicity determination of acidic, neutral, and basic compounds.

\section{ACKNOWLEDGEMENTS}

This work was supported by the Ministry of Economy and Competitiveness of Spain (project CTQ2014-56253-P). 


\section{CONFLICT OF INTEREST STATEMENT}

The authors declare no conflict of interest. 


\section{FIGURE LEGEND}

Figure 1. Normalized system coefficients of the Abraham equation for $\log P_{\mathrm{o} / \mathrm{w}}$ and $\log$ $k_{\text {MEEKC }}$ of the MEEKC systems studied. (A) this work; (B) data from ref. [16]. System references as in Table 2.

Figure 2. Linear correlations between $\log P_{\mathrm{o} / \mathrm{w}}$ and $\log k_{\mathrm{MEEKC}}$ obtained for some of the systems studied: (A) pH 2.0, 1.3\% SDS, 10\% ACN; (B) pH 7.4, 1.3\% SDS, 5\% ACN; (C) pH 10.0, 1.3\% SDS, 10\% ACN; and (D) $\mathrm{pH} 12.0,3.3 \% \mathrm{SDS}, 5 \% \mathrm{ACN}$. 


\section{REFERENCES}

[1] Ishihama, Y., Oda, Y., Uchikawa, K., Asakawa, N., Anal. Chem. 1995, 67, 1588-1595.

[2] Du, C. M., Valko, K., Bevan, C., Reynolds, D., Abraham, M. H., J. Liq. Chrom. \& Rel. Technol. 2001, 24, 635-649.

[3] Valko, K., Du, C. M., Bevan, C., Reynolds, D. P., Abraham, M. H., Curr. Med. Chem. 2001, 8, 1137-1146.

[4] Pallicer, J. M., Pous-Torres, S., Sales, J., Rosés, M., Ràfols, C., Bosch, E., J. Chromatogr. A 2010, 1217, 3026-3037.

[5] Kumar, P., Mittal, K. L., Handbook of microemulsion science and technology, Marcel Dekker, New York - Basel 1999.

[6] Ryan, R., Donegan, S., Power, J., McEvoy, E., Altria, K., Electrophoresis 2009, 30, 6582.

[7] Ryan, R., Donegan, S., Power, J., Altria, K., Electrophoresis 2010, 31, 755-767.

[8] Ryan, R., McEvoy, E., Sheila, D., Power, J., Altria, K., Electrophoresis 2011, 32, 184201.

[9] Ryan, R., Altria, K., McEvoy, E., Donegan, S., Power, J., ELECTROPHORESIS 2013, 34, 159-177.

[10]Riekkola, M. L., Jönsson, J. Å., Smith, R. M., Pure and Applied Chemistry 2004, p. 443.

[11]Bio-Loom, BioByte Corp. (Claremont, CA, USA), http://www.biobyte.com Version 1.5.

[12] Abraham, M. H., Chem. Soc. Rev. 1993, 22, 73-83.

[13]Abraham, M. H., Treiner, C., Rosés, M., Ràfols, C., Ishihama, Y., J. Chromatogr. A $1996,752,243-249$.

[14] Abraham, M. H., Chadha, H. S., Whiting, G. S., Mitchell, R. C., J. Pharm. Sci. 1994, 83, 1085-1100.

[15]Lázaro, E., Ràfols, C., Abraham, M. H., Rosés, M., J. Med. Chem. 2006, 49, 4861-4870.

[16]Poole, S. K., Durham, D., Kibbey, C., J. Chromatogr. B 2000, 745, 117-126.

[17]ACD/Labs Percepta, Advanced Chemistry Development (Toronto, Canada), www.acdlabs.com. Build 2726, 5 May 2014. 
TABLE 1

Table 1. Experimental $\log P_{\mathrm{o} / \mathrm{w}}$ values [11] and Abraham descriptors [17], and estimated $\mathrm{p} K_{\mathrm{a}}$ values (GALAS approach) [17] of the injected compounds.

\begin{tabular}{|c|c|c|c|c|c|c|c|}
\hline Solute & $\log P_{0 / w}$ & $\mathbf{p} K_{\mathrm{a}}$ & $E$ & $S$ & $A$ & $B$ & $V$ \\
\hline \multicolumn{8}{|l|}{ Acidic: } \\
\hline Pyrogallol & 0.21 & 9.0 & 1.17 & 1.35 & 1.35 & 0.62 & 0.893 \\
\hline Mandelic acid & 0.62 & 3.4 & 0.90 & 1.05 & 0.74 & 0.89 & 1.131 \\
\hline Gallic acid & 0.70 & 4.3 & 1.29 & 1.73 & 1.62 & 0.85 & 1.108 \\
\hline Resorcinol & 0.80 & 9.6 & 0.98 & 1.11 & 1.09 & 0.52 & 0.834 \\
\hline Catechol & 0.88 & 10.0 & 0.97 & 1.10 & 0.88 & 0.47 & 0.834 \\
\hline Aspirin & 1.19 & 3.5 & 0.78 & 0.80 & 0.49 & 1.00 & 1.288 \\
\hline 2,6-Dinitrophenol & 1.37 & 3.5 & 1.22 & 2.04 & 0.17 & 0.48 & 1.124 \\
\hline Phenol & 1.47 & 10.0 & 0.81 & 0.89 & 0.60 & 0.30 & 0.775 \\
\hline 4-Hydroxybenzoic acid & 1.58 & 4.6 & 0.93 & 0.90 & 0.81 & 0.56 & 0.990 \\
\hline 2,4-Dinitrophenol & 1.67 & 4.2 & 1.20 & 1.49 & 0.09 & 0.56 & 1.124 \\
\hline 2,5-Dinitrophenol & 1.75 & 5.2 & 1.26 & 1.45 & 0.11 & 0.54 & 1.124 \\
\hline 3-Nitrobenzoic acid & 1.83 & 3.4 & 0.99 & 1.11 & 0.74 & 0.53 & 1.106 \\
\hline Benzoic acid & 1.87 & 4.1 & 0.73 & 0.90 & 0.59 & 0.40 & 0.932 \\
\hline 4-Nitrobenzoic acid & 1.89 & 3.3 & 0.99 & 1.07 & 0.68 & 0.54 & 1.106 \\
\hline 4-Nitrophenol & 1.91 & 7.2 & 1.07 & 1.72 & 0.82 & 0.26 & 0.949 \\
\hline Terephthalic acid & 2.00 & 3.5 & 0.94 & 1.46 & 1.14 & 0.77 & 1.147 \\
\hline Cinnamic acid & 2.13 & 4.4 & 1.14 & 1.00 & 0.58 & 0.57 & 1.171 \\
\hline Dinitrocresol & 2.13 & 4.2 & 1.20 & 1.47 & 0.09 & 0.55 & 1.264 \\
\hline 2,4-Dimethylbenzoic acid & 2.20 & 3.7 & 0.73 & 0.90 & 0.59 & 0.36 & 1.214 \\
\hline 2,4-Dimethylphenol & 2.30 & 10.0 & 0.84 & 0.80 & 0.53 & 0.39 & 1.057 \\
\hline 3-Methylbenzoic acid & 2.37 & 4.1 & 0.73 & 0.90 & 0.60 & 0.40 & 1.073 \\
\hline 2-Methylbenzoic acid & 2.40 & 3.7 & 0.73 & 0.90 & 0.64 & 0.36 & 1.073 \\
\hline Estriol & 2.54 & 10.0 & 1.97 & 1.74 & 1.06 & 1.63 & 2.258 \\
\hline Isoeugenol & 2.58 & 10.0 & 0.95 & 1.05 & 0.22 & 0.64 & 1.354 \\
\hline 3-Bromobenzoic acid & 2.87 & 3.6 & 1.00 & 1.10 & 0.64 & 0.27 & 1.107 \\
\hline 1-Naphthoic acid & 3.10 & 3.5 & 1.46 & 1.20 & 0.65 & 0.46 & 1.301 \\
\hline Ketoprofen & 3.12 & 4.1 & 1.65 & 2.26 & 0.55 & 0.89 & 1.978 \\
\hline Estrone & 3.13 & 9.9 & 1.73 & 2.05 & 0.50 & 1.08 & 2.156 \\
\hline Fenbufen & 3.20 & 4.8 & 1.78 & 1.80 & 0.62 & 1.05 & 1.978 \\
\hline 3,5-Dichlorobenzoic acid & 3.29 & 3.6 & 1.15 & 1.17 & 0.70 & 0.41 & 1.177 \\
\hline Ibuprofen & 3.50 & 4.3 & 0.73 & 0.59 & 0.59 & 0.81 & 1.777 \\
\hline 4-tert-Butylbenzoic acid & 3.85 & 4.1 & 0.73 & 0.84 & 0.59 & 0.41 & 1.495 \\
\hline Estradiol & 4.01 & 10.0 & 1.80 & 1.77 & 0.86 & 1.10 & 2.199 \\
\hline Flurbiprofen & 4.16 & 4.1 & 1.50 & 1.51 & 0.57 & 0.58 & 1.839 \\
\hline Pentachlorophenol & 5.12 & 4.5 & 1.27 & 1.13 & 0.70 & 0.00 & 1.387 \\
\hline Retinoic acid & 6.30 & 4.4 & 1.03 & 0.98 & 0.57 & 0.80 & 2.677 \\
\hline \multicolumn{8}{|l|}{ Basic: } \\
\hline 4-Aminobenzamide & -0.41 & 2.4 & 1.34 & 1.94 & 0.80 & 0.94 & 1.073 \\
\hline Pyrimidine & -0.40 & 1.6 & 0.61 & 0.93 & 0.00 & 0.67 & 0.634 \\
\hline Atenolol & 0.17 & 9.5 & 1.45 & 1.88 & 0.69 & 2.00 & 2.176 \\
\hline Antipyrine & 0.23 & 1.8 & 1.32 & 1.50 & 0.00 & 1.48 & 1.485 \\
\hline$N$-Phenylthiourea & 0.73 & 1.4 & 1.25 & 1.69 & 0.48 & 0.79 & 1.177 \\
\hline 4-Nitroaniline & 1.39 & 1.2 & 1.22 & 1.93 & 0.46 & 0.35 & 0.990 \\
\hline Metoprolol & 1.88 & 9.5 & 1.17 & 1.33 & 0.17 & 1.76 & 2.260 \\
\hline
\end{tabular}




\begin{tabular}{|c|c|c|c|c|c|c|c|}
\hline 3-Chloroaniline & 2.02 & 3.5 & 1.05 & 1.10 & 0.30 & 0.30 & 0.939 \\
\hline Lidocaine & 2.21 & 7.9 & 1.01 & 1.50 & 0.12 & 1.21 & 2.059 \\
\hline Benzanilide & 2.62 & 1.3 & 1.76 & 1.87 & 0.42 & 0.73 & 1.581 \\
\hline Haloperidol & 4.28 & 8.7 & 1.90 & 1.39 & 0.40 & 1.76 & 2.798 \\
\hline \multicolumn{8}{|l|}{ Neutral: } \\
\hline Acetamide & -1.09 & - & 0.46 & 1.30 & 0.54 & 0.68 & 0.506 \\
\hline$N, N$-Dimethylacetamide & -0.77 & - & 0.36 & 1.35 & 0.00 & 0.77 & 0.788 \\
\hline Caffeine & -0.07 & - & 1.50 & 1.72 & 0.05 & 1.28 & 1.363 \\
\hline Benzamide & 0.64 & - & 0.99 & 1.50 & 0.49 & 0.67 & 0.973 \\
\hline Pyrrole & 0.75 & - & 0.61 & 0.91 & 0.22 & 0.25 & 0.577 \\
\hline N-Phenylurea & 0.83 & - & 1.11 & 1.33 & 0.79 & 0.79 & 1.073 \\
\hline Benzyl alcohol & 1.10 & - & 0.80 & 0.87 & 0.39 & 0.56 & 0.916 \\
\hline Acetanilide & 1.16 & - & 0.90 & 1.39 & 0.48 & 0.67 & 1.114 \\
\hline Coumarin & 1.39 & - & 1.06 & 1.76 & 0.00 & 0.43 & 1.062 \\
\hline Prednisolone & 1.42 & - & 2.21 & 3.10 & 0.71 & 1.92 & 2.755 \\
\hline Benzaldehyde & 1.47 & - & 0.82 & 1.00 & 0.00 & 0.39 & 0.873 \\
\hline Cortisone & 1.47 & - & 1.96 & 3.50 & 0.36 & 1.87 & 2.755 \\
\hline Acetophenone & 1.58 & - & 0.82 & 1.01 & 0.00 & 0.48 & 1.014 \\
\hline Hydrocortisone & 1.61 & - & 2.03 & 3.50 & 0.71 & 1.90 & 2.798 \\
\hline Nitrobenzene & 1.85 & - & 0.87 & 1.11 & 0.00 & 0.28 & 0.891 \\
\hline 2-Nitroanisole & 2.06 & - & 0.97 & 1.34 & 0.00 & 0.45 & 1.090 \\
\hline Anisole & 2.11 & - & 0.71 & 0.75 & 0.00 & 0.29 & 0.916 \\
\hline 4-Chloroacetanilide & 2.12 & - & 0.98 & 1.47 & 0.64 & 0.51 & 1.236 \\
\hline Benzene & 2.13 & - & 0.61 & 0.52 & 0.00 & 0.14 & 0.716 \\
\hline Propiophenone & 2.19 & - & 0.80 & 0.95 & 0.00 & 0.51 & 1.155 \\
\hline Butyrophenone & 2.66 & - & 0.80 & 0.95 & 0.00 & 0.51 & 1.296 \\
\hline Benzofuran & 2.67 & - & 0.89 & 0.83 & 0.00 & 0.15 & 0.905 \\
\hline Toluene & 2.73 & - & 0.60 & 0.52 & 0.00 & 0.14 & 0.857 \\
\hline Bromobenzene & 2.99 & - & 0.88 & 0.73 & 0.00 & 0.09 & 0.891 \\
\hline 4-Ethylnitrobenzene & 3.03 & - & 0.85 & 1.21 & 0.00 & 0.22 & 1.172 \\
\hline Ethylbenzene & 3.15 & - & 0.61 & 0.51 & 0.00 & 0.15 & 0.998 \\
\hline Valerophenone & 3.17 & - & 0.80 & 0.95 & 0.00 & 0.50 & 1.437 \\
\hline Naphthalene & 3.30 & - & 1.34 & 0.92 & 0.00 & 0.20 & 1.085 \\
\hline 1,2,4-Trimethylbenzene & 3.63 & - & 0.68 & 0.56 & 0.00 & 0.19 & 1.139 \\
\hline Propylbenzene & 3.72 & - & 0.60 & 0.50 & 0.00 & 0.15 & 1.139 \\
\hline Progesterone & 3.87 & - & 1.45 & 3.29 & 0.00 & 1.14 & 2.622 \\
\hline Pregnenolone & 4.22 & - & 1.36 & 3.29 & 0.32 & 1.18 & 2.665 \\
\hline Butylbenzene & 4.38 & - & 0.60 & 0.51 & 0.00 & 0.15 & 1.280 \\
\hline Anthracene & 4.45 & - & 2.29 & 1.34 & 0.00 & 0.28 & 1.454 \\
\hline Phenanthrene & 4.47 & - & 2.06 & 1.29 & 0.00 & 0.29 & 1.454 \\
\hline Pyrene & 4.88 & - & 2.60 & 1.52 & 0.00 & 0.25 & 1.585 \\
\hline Pentylbenzene & 4.90 & - & 0.59 & 0.51 & 0.00 & 0.15 & 1.421 \\
\hline Pentachloronitrobenzene & 5.10 & - & 1.47 & 1.70 & 0.00 & 0.01 & 1.503 \\
\hline
\end{tabular}

Estimated values marked in italics. 
TABLE 2

Table 2. System coefficients (Eq. (2)) and $d$ distance between MEEKC and reference $\log P_{\mathrm{o} / \mathrm{w}}$ (Eq. (4)) systems.

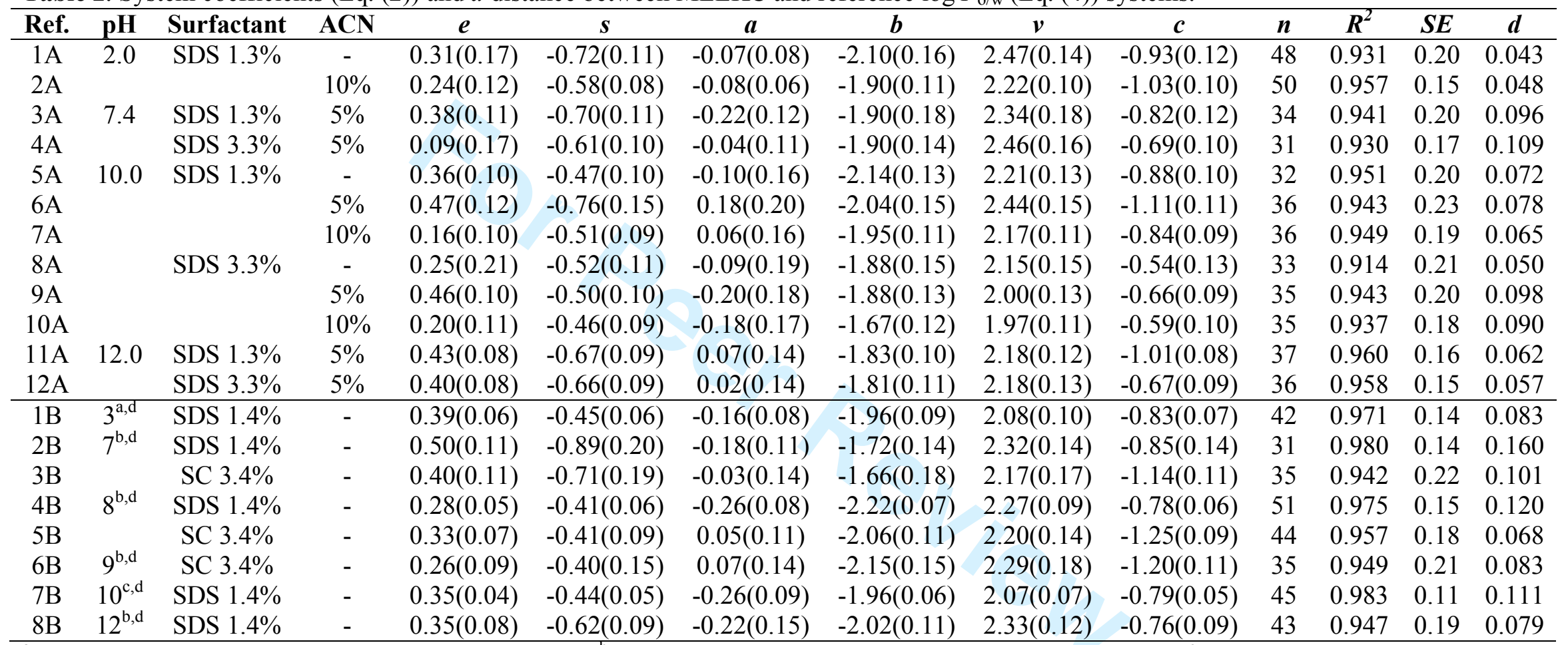

${ }^{\mathrm{a}} 50 \mathrm{mM}$ sodium phosphate + phosphoric acid $(85 \%) ;{ }^{b} 50 \mathrm{mM}$ sodium phosphate + sodium hydroxide $(1 \mathrm{M}) ;{ }^{\mathrm{c}} 20 \mathrm{mM}$ sodium borate $+30 \mathrm{mM}$ sodium phosphate; ${ }^{\mathrm{d}}$ molecular descriptors and $\log k$ values from ref. [16], measurements made at $30^{\circ} \mathrm{C}$, ME consisting of $1.4 \%$ (w/v) $\mathrm{SDS}$ or $3.4 \%(\mathrm{w} / \mathrm{v})$ of SC, $8 \%(\mathrm{v} / \mathrm{v}) 1$-butanol, and $1.2 \%(\mathrm{v} / \mathrm{v})$ heptane. 
(A)

$e_{\mathrm{u}}$

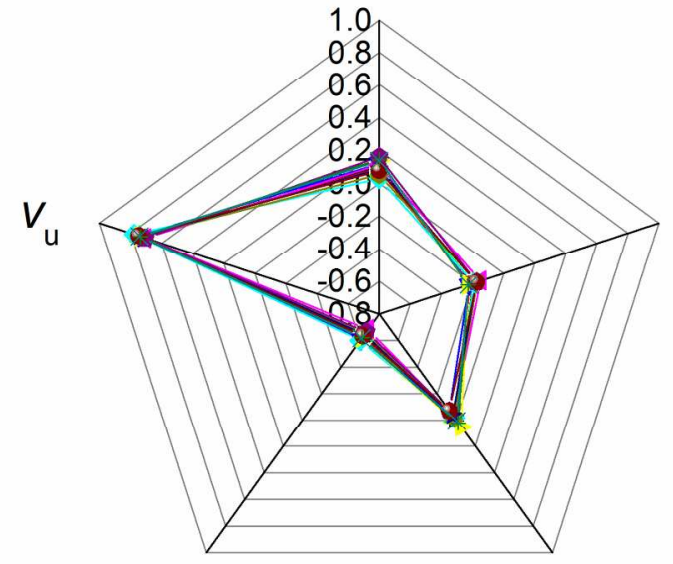

$$
\begin{array}{cl} 
& -\log P_{\mathrm{o} / \mathrm{w}} \\
& -1 \mathrm{~A} \\
& --2 \mathrm{~A} \\
S_{\mathrm{u}} & --3 \mathrm{~A} \\
& -4 \mathrm{~A} \\
-5 \mathrm{~A} \\
-6 \mathrm{~A} \\
-7 \mathrm{~A} \\
--8 \mathrm{~A} \\
--10 \mathrm{~A} \\
-+11 \mathrm{~A} \\
-\times-12 \mathrm{~A}
\end{array}
$$

$b_{\mathrm{u}}$

$a_{\mathrm{u}}$
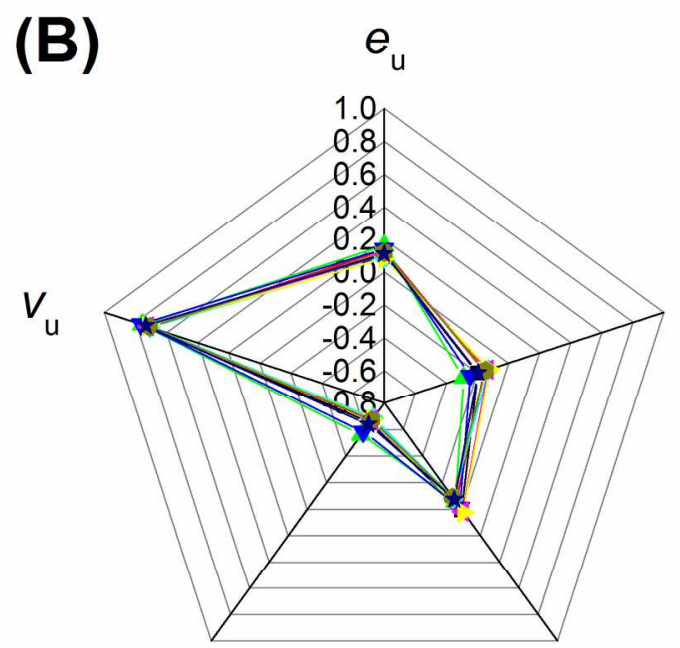

$$
\begin{aligned}
& -\square-\log P_{\mathrm{o} / \mathrm{w}} \\
& -\bullet 1 \mathrm{~B}
\end{aligned}
$$

$S_{\mathrm{u}}$

$$
-\triangle-2 B
$$

$-\nabla-3 \mathrm{~B}$

$\rightarrow 4 B$

$-4-5 \mathrm{~B}$

- $6 \mathrm{~B}$

$\longrightarrow 7 \mathrm{~B}$

- - 8B

$b_{\mathrm{u}}$

$a_{\mathrm{u}}$

Figure 1. Normalized system coefficients of the Abraham equation for log Po/w and log kMEEKC of the MEEKC systems studied. (A) this work; (B) data from ref. [16]. System references as in Table 2. $172 \times 263 \mathrm{~mm}(300 \times 300 \mathrm{DPI})$ 

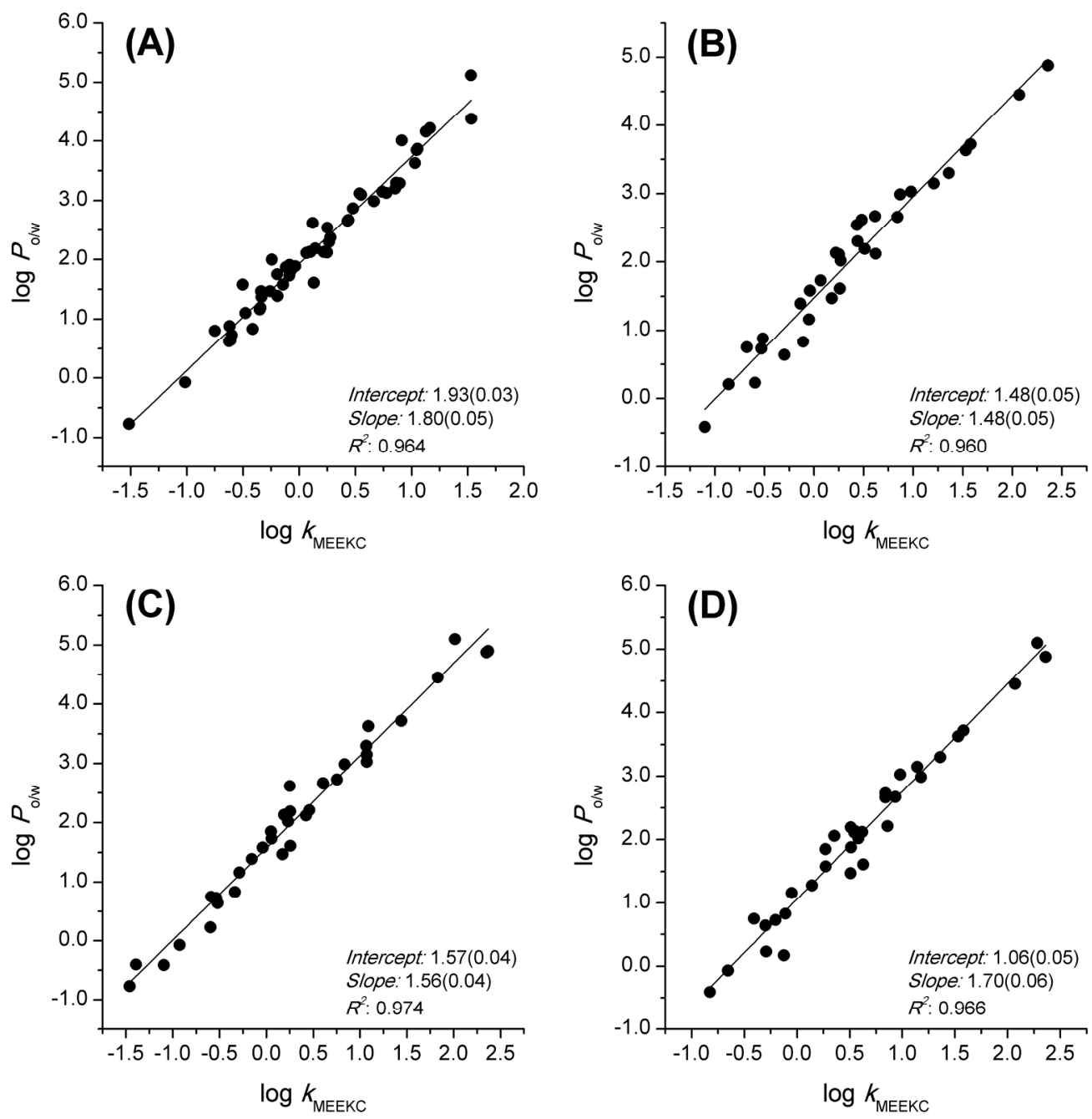

Figure 2. Linear correlations between log Po/w and log kMEEKC obtained for some of the systems studied: (A) $\mathrm{pH} 2.0,1.3 \%$ SDS, $10 \%$ ACN; (B) $\mathrm{pH} 7.4,1.3 \%$ SDS, 5\% ACN; (C) $\mathrm{pH} 10.0,1.3 \%$ SDS, $10 \%$ ACN; and (D) $\mathrm{pH} 12.0,3.3 \%$ SDS, $5 \%$ ACN. $205 \times 210 \mathrm{~mm}(300 \times 300 \mathrm{DPI})$ 